\title{
BERTUCCI, Liane Maria; FARIA FILHO, Luciano Mendes de; OLIVEIRA, Marcus Aurélio Taborda de. Edward Thompson: história e formação. Belo Horizonte: Editora UFMG, 2010. 121 p.
}

\author{
Renata Vieira da Cunha*
}

No livro Edward P. Thompson: história e formação, escrito por Liane Maria Bertucci, Luciano Mendes de Faria Filho e Marcus Aurélio Taborda de Oliveira, os autores analisam as contribuições do pensamento do historiador inglês Edward Thompson para as pesquisas na área de História da Educação. Os autores justificam a organização deste livro pela constatação de que apesar da obra de Edward Thompson estar presente nas áreas de História e de Ciências Sociais ela ainda é pouco recorrida nos trabalhos que tratam da história da educação no Brasil. Para os autores, os escritos de Thompson podem ajudar na problematização do processo educativo. No entanto, afirmam que não pretendem pedagogizar as obras do referido teórico, já que destacam o fato de que o autor em questão não escreveu para professores, não produziu material de caráter didático, nem atuou na formação de professores e em universidades. Mas, apesar disso, afirmam que Thompson propôs reflexões muito importantes que devem ser conhecidas tanto por professores como por pesquisadores, uma vez que nos ajudam a refletir sobre a cultura, a educação, os processos de formação e sobre a escolarização.

O livro Edward P. Thompson: história e formação foi elaborado em três capítulos, que oferecem uma iniciação de e sobre o legado de Thompson para a pesquisa em educação no Brasil. A obra é finalizada "com um breve conjunto de notas apresentando alguns trabalhos publicados no Brasil sobre Edward Thompson e sua obra." (BERTUCCI; FARIA FILHO E OLIVEIRA, 2010, p. 14).

No primeiro capítulo, os autores discutem a contribuição de Thompson como historiador destacado da cultura e da sociedade, oferecendo ao leitor as possibilidades de utilizar os escritos do historiador inglês tanto na Educação como em outras áreas. Localizam, além disso, diferentes tradições historiográficas em seu debate, ressaltando que

\footnotetext{
* Graduada em História pela PUC Minas e mestranda em Educação pela Universidade Federal de Minas Gerais.
} 
Edward Thompson foi o historiador que inaugurou um dos desdobramentos da história social: a "história vista de baixo", que, por sua vez, colaborou, direta e indiretamente, para a implementação de alguns caminhos da pesquisa histórica, como a micro história e a história oral. (BERTUCCI; FARIA FILHO; OLIVEIRA, 2010, p. 23).

De acordo com os autores, Thompson colaborou para o estudo das pessoas comuns, que com suas experiências foram agentes da história, e cujas ações afetaram, em diferentes graus, o mundo em que viveram e deixaram para seus filhos. Esta lição é apontada por Liane Bertucci, Luciano Mendes e Marcus Taborda como preciosa para todos os historiadores, inclusive os da área da educação.

Durante o texto, são apresentadas ao leitor discussões sobre algumas das mais consagradas obras do referido historiador inglês. A respeito do livro A formação da classe operária inglesa, publicado em 1963, atribuem a Thompson a busca por indícios de como as pessoas vivenciaram suas experiências cotidianas marcadas pelo tempo e pelo espaço em que estavam. E, além disso, como se fizeram, forjando assim a sua história enquanto indivíduos, que, vivendo em sociedade, formaram um grupo com ideias e interesses comuns - uma classe. Seus estudos sobre a formação da classe operária inglesa foram, em grande parte, motivados e fecundados pelos diálogos com seus alunos (operários e sindicalistas), na escola noturna em que trabalhou. Assim, para Thompson, a classe operária é parte do processo histórico que resultou na indústria moderna e os operários são vistos como sujeitos desse processo histórico e não como vítimas dele. Além disso, ao buscar as pessoas que fizeram a classe operária inglesa, rejeitou a supremacia do aspecto econômico sobre o sociocultural, contestando a maneira como o conceito "modo de produção" foi interpretado entre diversos historiadores e cientistas sociais.

Além de possuir como metodologia a busca da experiência dos homens em sociedade, os autores do livro Edward P. Thompson: história e formação destacam que o historiador inglês explorou de forma inédita em seus escritos documentos até então pouco utilizados pela historiografia. Sua pesquisa incluiu jornais, panfletos e livros, registros de debates parlamentares, leis e ordens judiciais, atas de associações, clubes, sociedades e sindicatos, coleções de cartas e diários pessoais guardados por particulares, canções antigas compiladas por folcloristas cujos temas, de alguma forma, visavam os trabalhadores. Por isso, a leitura de Thompson é tida como útil no questionamento sobre o que considerar documento para o estudo histórico da escola e dos processos educacionais. 
No caso específico de A miséria da teoria (1981), salientam que Thompson explicitou sua concepção de história e como fazê-la. Ao criticar Louis Althusser e sua leitura estruturalista do marxismo, afirmava que a reflexão teórica só deve ser concebida na própria pesquisa da história. Para ele, a teoria era permanentemente refeita na relação indispensável com as fontes, num diálogo conduzido por hipóteses ancoradas pela teoria, como também pela pesquisa empírica.

Já em Senhores e caçadores (1987) os analistas inferem que o historiador inglês adentrou o universo da sociedade inglesa do início do século XVIII buscando entender a promulgação da Lei negra de 1723 e a forma de sua aplicação. Assim, nesse trabalho, percebeu como as leis em desuso passaram a ser invocadas e, mais ainda, como ganharam reforço de uma nova legislação. Apontou também como os atos até então pautados pelo costume passaram a ser cada vez mais marcados pela nova Lei e pela nova forma de aplicá-la. Traz então um significativo alerta a ser considerado pelos historiadores da educação de que a Lei não foi apenas imposta sobre os homens, mas tem desencadeado outros conflitos sociais.

Os autores consideram que os temas da Lei e do direito estão presentes também em uma coletânea de textos sobre o século XVIII intitulada Costumes em comum (1998). Fixando-se no costume e no cotidiano, esse livro aborda a questão legal e o direito como parte do dia a dia de homens e mulheres, os quais, muitas vezes, entram em conflito com a cultura popular tradicional.

No segundo capítulo, intitulado Experiência e Cultura em Thompson: contribuições para uma história social da escolarização são apresentadas possibilidades de investigar a história escolar, operando com conceitos e métodos thompsonianos. Os autores recorrem às noções-chave aprofundadas por Thompson, isto é, "cultura" e "experiência" - para pensar o processo de escolarização como uma experiência histórica e não predefinida. Afirmam que Thompson busca entender também a forma como estrutura e processo se articulam na história ao propor que a história não é predeterminada, caracterizando-a como a ação criativa dos homens e mulheres que a fazem. Apesar disso, o historiador inglês considera que toda ação humana é condicionada (e não determinada) pela estrutura social em que está inserida. Todavia, tal condicionamento, ao invés de determinar, impõe limites, estabelece condições para a ação sempre criativa dos homens e mulheres na história. Nesse sentido, os autores apontam que é possível pensar, com Thompson, para além da história da escola contemporânea, ou seja, também 
[...] o estudo das multifacetadas transformações que tiveram lugar nas sociedades modernas, na transição de uma sociedade sem escolas (no atual sentido da palavra) para as sociedades plenamente escolarizadas contemporâneas. (BERTUCCI; FARIA FILHO; OLIVEIRA, 2010, p. 46).

Parafraseando Thompson, os autores afirmam que a tensão que marca o processo de escolarização assinala a totalidade da cultura, haja vista que o projeto educativo posto em ação na e pela escola entra em tensão com processos educativos já existentes. Isso porque as culturas escolares são na verdade o resultado das experiências dos sujeitos, dos sentidos construídos, compartilhados, e, muitas vezes, disputados pelos atores que fazem a história.

Apesar de apontarem possibilidades para os historiadores da educação trabalharem com os conceitos thompsoniamos, os autores esclarecem que um dos únicos textos em que Thompson trata diretamente da educação é em Os românticos (2002), onde extrapola os limites da escola e da sala de aula, para buscar a educação que se constrói no âmbito das relações sociais.

\begin{abstract}
Thompson advoga que o desprezo que a cultura letrada construiu e divulgou em relação às experiências das camadas mais pobres da população, inclusive no que se refere aos processos educativos aí ocorridos, não era a única possibilidade posta no início da escolarização. (BERTUCCI; FARIA FILHO; OLIVEIRA, 2010, p. 64).
\end{abstract}

Ainda em Os românticos, apresenta a possibilidade de se pensar em outra escola, onde professores tornem-se aprendizes e que dialoguem de forma menos preconceituosa com as outras experiências dos alunos e alunas.

No terceiro e último capítulo do livro, os autores aprofundam a noção do fazerse, a fim de buscar entender como a escolarização pode produzir um sujeito que ao mesmo tempo em que é formado para perpetuar a sociedade, a ela resiste. Bertucci; Faria Filho e Oliveira interpretam que ao longo de seus escritos, Thompson deixa claro que os sujeitos se constituem, ou seja, se formam, se educam, nas mais diferenciadas circunstâncias em que vivem, tanto no trabalho, na família, na comunidade, no lazer e em vários outros lugares. Para ele, a experiência deve ser pensada entre a determinação e a apropriação, entre a estrutura e o processo, entre a singularidade e a generalização. E mais do que isso, a experiência pode estabelecer a conexão entre processo histórico, determinações culturais e ação humana individual.

Mais do que apresentar Thompson, os autores dessa coletânea, inspirados pela forma de produzir desse historiador, discutem, a partir de suas contribuições originais, 
alguns problemas contemporâneos afeitos à educação, à escolarização e à história da educação. À luz dos conceitos de Thompson, propõem ao leitor pensar sempre na ação conjugada da escola com as demais instituições sociais na formação dos sujeitos, como também, no modo como os sujeitos se colocam no processo de escolarização, com suas vivências e aspirações.

A leitura da obra em análise também provoca algumas indagações nos leitores: Qual seria hoje o papel fundamental da escola? Seria possível hoje conceber a escola além de um espaço de instrução nos termos propostos por Thompson, principalmente em seu entendimento do fazer-se? A leitura de Thompson feita por Bertucci; Faria Filho e Oliveira nos leva a pensar que a história pode ser diferente, já que através de um contínuo fazer-se, inclusive escolar, a sociedade pode se organizar em outras bases. 